\title{
Sex determination in insects: variations on a common theme
}

\author{
Bopp, D ; Saccone, G ; Beye, M
}

\begin{abstract}
Recent studies in a representative selection of holometabolous insects suggest that, despite diversity at the instructive level, the signal-relaying part of the sex-determining pathway is remarkably well conserved. In principle, it is composed of the transformer gene (tra), which acts as a common binary switch that transduces the selected sexual fate, female when ON, male when OFF, to the downstream effector doublesex (dsx) that controls overt sexual differentiation. An interesting recurrent feature is that tra is switched ON in the early zygote by maternally provisioned tra activity. Different male-determining signals evolved, which prevent maternal activation of zygotic tra to allow for male development. In some species, where lack of maternal activation leaves tra in the OFF state, novel female-determining signals were deployedto activate zygotic tra. It appears that both the instructive end of the pathway upstream of tra as well as the executive end downstream of dsx are primary targets of evolutionary divergence, while the transduction part seems less prone to changes. We propose that this is a feature shared with many other signaling cascades that regulate developmental fates.
\end{abstract}

DOI: https://doi.org/10.1159/000356458

Posted at the Zurich Open Repository and Archive, University of Zurich ZORA URL: https://doi.org/10.5167/uzh-138656

Journal Article

Published Version

Originally published at:

Bopp, D; Saccone, G; Beye, M (2014). Sex determination in insects: variations on a common theme. Sexual Development, 8(1-3):20-28.

DOI: https://doi.org/10.1159/000356458 


\title{
Sex Determination in Insects:
} Variations on a Common Theme

\author{
D. Bopp ${ }^{a} \quad$ G. Saccone ${ }^{b} \quad$ M. Beye ${ }^{c}$
}

${ }^{a}$ Institute of Molecular Life Sciences, University of Zurich, Zurich, Switzerland; ${ }^{b}$ Dipartimento di Biologia, Università degli Studi di Napoli 'Federico II', Naples, Italy; 'Institute of Evolutionary Genetics, Heinrich Heine University Düsseldorf, Düsseldorf, Germany

\section{Key Words}

Doublesex · Evolution · Holometabolous insects $\cdot$ RNA

splicing $\cdot$ Sex determination $\cdot$ Transformer

\begin{abstract}
Recent studies in a representative selection of holometabolous insects suggest that, despite diversity at the instructive level, the signal-relaying part of the sex-determining pathway is remarkably well conserved. In principle, it is composed of the transformer gene (tra), which acts as a common binary switch that transduces the selected sexual fate, female when ON, male when OFF, to the downstream effector doublesex $(d s x)$ that controls overt sexual differentiation. An interesting recurrent feature is that tra is switched $\mathrm{ON}$ in the early zygote by maternally provisioned tra activity. Different male-determining signals evolved, which prevent maternal activation of zygotic tra to allow for male development. In some species, where lack of maternal activation leaves tra in the OFF state, novel female-determining signals were deployed to activate zygotic tra. It appears that both the instructive end of the pathway upstream of tra as well as the executive end downstream of $d s x$ are primary targets of evolutionary divergence, while the transduction part seems less prone to changes. We propose that this is a feature shared with many other signaling cascades that regulate developmental fates.

(c) 2013 S. Karger AG, Basel
\end{abstract}

\section{Coordinate Control of Sexually Dimorphic Development}

Proper assignment of a sexual identity is critical for the individual to develop into a reproductively successful organism, since many aspects of development need to be reconciled with this decision. Not only the 2 sexes differ with respect to the gamete-producing tissues, ovaries in females and testes in males, but often they also display considerable differences in morphology, anatomy as well as in various aspects of their physiology. Moreover, the decision to become a male or female has also an impact on the development of the CNS, e.g. on the building of neuronal circuitries which specify sex-specific behaviors. In essence, dimorphic development results from differences in the phenotypic manifestation of practically the same genome. Hence, a key question is how is the sexual fate determined and how is this coordinately controlled at the whole organismal level? In principle, there are 2 modes of how this global coordination can be achieved. On the one hand, proper sexual differentiation can be controlled by nonautonomous systemic cues, e.g. through sex hormones produced by the prespecified gonads in vertebrates [Camerino et al., 2006; Wilhelm et al., 2007] or through cell-by-cell assessment of a sex-determining signal in a cell-autonomous fashion [Sánchez and Nöthiger, 1982; Cline, 1993]. In the latter case, the sexual

\section{KARGER}

E-Mail karger@karger.com

www.karger.com/sxd
(C) 2013 S. Karger AG, Basel

1661-5425/13/0083-0020\$38.00/0
Daniel Bopp

University of Zurich, Institute of Molecular Life Sciences

Winterthurerstrasse 190

CH-8057 Zurich (Switzerland)

E-Mail daniel.bopp@imls.uzh.ch 
fate is irreversibly fixed at a very early stage in development and inherited to all descending cell lineages. The genetic logic of how cells are instructed and implement this decision has been extensively studied in Drosophila. From these studies, it was deduced that the pathway is composed of 3 hierarchically arranged levels: on top the assessment of the signal (instruction), followed by fixing and memorizing the selected fate (autoregulation, epigenetic mechanisms) through genetic switches (transduction) and at the bottom the realization of the program by global effectors (execution).

In insects, we find a bewildering diversity at the level of the instructive signal [Schütt and Nöthiger, 2000; Saccone et al., 2002; Sánchez, 2008; Bopp, 2010; Nagaraju and Saccone, 2010; Verhulst et al., 2010b; Gempe and Beye, 2011]. For instance, while many species involve dominant Mendelian cues, they can be either male-determining (usually referred to as $\mathrm{M}$, e.g many dipteran insects such as the housefly, Musca domestica) or female-determining (referred to as F, e.g. butterflies). In a large number of species, the fertilization process determines the sexual fate (e.g. wasps, ants and bees): males are derived from unfertilized eggs that are haploid, and females develop from fertilized eggs that are diploid [Gempe and Beye, 2011]. In yet other cases, it is the genotype of the mother that decides whether her progeny will be male or female [Ullerich, 1984]. Some species even involve environmental cues, e.g. temperature, population density or nutritional status, to resolve the sexual fate of the embryo. In the best-documented case, $D$. melanogaster, the embryo bases this decision on the numbers of $\mathrm{X}$ chromosomes present in the diploid zygote: the presence of $2 \mathrm{X}$ chromosomes imposes female development, while male development follows when only $1 \mathrm{X}$ is present [Cline and Meyer, 1996; Erickson and Quintero, 2007]. This rather peculiar practice of counting $\mathrm{X}$ chromosomes as a signal for determining the sex appears to be common to drosophilids but has found few followers outside the genus Drosophila [Cline et al., 2010]. The primary sex-determining signal in the honeybee, Apis mellifera, constitutes of a single locus and its multiple allelic variants [Beye et al., 2003; Gempe et al., 2009]. Heterozygosity determines femaleness, whereas a single allele (as found in unfertilized, haploid eggs) or the same alleles impose maleness. The various sex-determining signals found in the housefly, $M$. domestica, document best the remarkable plasticity of this pathway. Strains with different male determiners and a female determiner can coexist in natural populations [Dübendorfer et al., 2002; Hediger et al., 2010].

Sex Determination in Insects
To account for divergent evolution, Wilkins [1995] proposed that sex-determining pathways evolve by a stepby-step incorporation of new upstream components in preexisting pathways. Nevertheless, the existence of so many different types of signals was surprising when considering that the need for a regulatory mechanism that controls and coordinates dimorphic development is universal in the animal kingdom and may have existed since the dawn of anisogamous reproduction. Here, we review recent advances in understanding how differences in the sex-determining pathways arose from an existing repertoire of genes. Diversification seems to be largely based on varying the primary sex determination signals, but leaving the transductory components downstream unaltered. In this review, we will present and discuss latest findings from studies in a small but phylogenetically informative selection of holometabolous insects. This selection comprises members of different insect orders and reflects divergent insect evolution of the last 260 million years. The results of this studies did not only reveal regulatory diversity, but also shared principles and, most interestingly, provided a framework to explain the evolutionary routes which have been taken to generate the diversity of sex determination systems found in today's insects.

\section{Insects Employ a Conserved Module in Transducing Sex-Determining Instructions}

A key finding from these studies is that the pathways share a conserved switch, the transformer gene (tra). Its pivotal role as the global switch in sex determination (ON - female development, OFF - male development) has been experimentally confirmed in members of insect orders as distant as Diptera and Hymenoptera [O'Neil and Belote, 1992; Shearman and Frommer, 1998; Pane et al., 2002; Lagos et al., 2007; Ruiz et al., 2007b; Concha and Scott, 2009; Gempe et al., 2009; Hediger et al., 2010; Shukla and Nagaraju, 2010; Verhulst et al., 2010b; Shukla and Palli, 2012b]. From these findings, it can be inferred that tra must have already adopted a pivotal sex-determining function before divergence of the main insect orders. It is thus likely that tra is a part of an ancestral module, which relays the instructive signals to downstream effectors. The gene doublesex $(d s x)$ has been identified as a prime target of tra in all insect systems studied so far [Burtis and Baker, 1989; Shearman and Frommer, 1998; Kuhn et al., 2000; Ohbayashi et al., 2001; Suzuki et al., 2001; Hediger et al., 2004; Scali et al., 2005; Ruiz et al., 2007a; Oliveira et al., 2009; Concha et al., 2010; Shukla and Nagaraju, 2010; 
Salvemini et al., 2011; Shukla and Palli, 2012a]. In addition, there is growing evidence which suggests that the pathway below tra bifurcates employing a different target, the fruitless gene (fru), for sex-specific differentiation of CNS-related aspects such as male courtship behavior [Bertossa et al., 2009; Salvemini et al., 2010; Clynen et al., 2011; Meier et al., 2013]. Hence, the ancestral module may have consisted of tra and possibly both effectors $d s x$ and fru to faithfully implement the sexual programs imposed by the instructive signals. Tra also plays a crucial part in maintaining the selected fate epigenetically [Saccone et al., 2011]. It acts as a cellular memory for female development, a key feature first discovered in Ceratitis [Pane et al., 2002]. Once activated by a female signal, tra will perpetuate its female-promoting functions by engaging a positive feedback loop that locks tra into the ON state. Evidence for such an autoregulatory function of tra has been found in a number of different insect species [Pane et al., 2002, 2005; Lagos et al., 2007; Concha and Scott, 2009; Gempe et al., 2009; Hediger et al., 2010; Sarno et al., 2010; Verhulst et al., 2010a] with the notable exception of D. melanogaster and possibly other drosophilids [Bopp et al., 1996; Cline et al., 2010]. Here, it is the gene Sex lethal (Sxl), a more recently acquired upstream regulator of tra, which performs the task of sustaining the female-promoting functions of tra (see below).

A common feature in all insect systems investigated so far is that the ON/OFF regulation of tra is achieved at the level of splicing as illustrated in figure 1. A female signal generates tra splice variants with an intact ORF that encodes the female-promoting activity. Presence of a male signal, on the other hand, leads to the incorporation of additional sequences into the mature RNA that introduce in-frame stop signals. The resulting male-specific splice variants contain a truncated open reading frame and are functionally inactive. The gene product of tra itself is a splice regulator that is needed to uphold tra's productive female mode of splicing. In cells committed to the male fate, $\mathrm{tra}$ is locked into the nonproductive mode of splicing due to the absence of functional tra activity. It thus appears that the ON/OFF setting of the switch largely depends on whether an early supply of functional TRA is present or not to engage the self-sustaining loop. Hence, the decision to become a male or female entirely depends on the splicing state of zygotic tra.

We propose that it is this crucial aspect of tra ON/OFF regulation that has become the prime target for diversification (fig. 1). The most direct way to activate zygotic tra and engage the positive feedback loop is to provide maternal tra products as a loop starter to the zygote. This modus operandi has been suggested for tra activation in the dipteran species C. capitata and $M$. domestica [Pane et al., 2002; Hediger et al., 2010], in the hymenopteran species Nasonia vitripennis [Verhulst et al., 2010a] and more recently also in the coleopteran species Tribolium castaneum (fig. 1) [Shukla and Palli, 2012b]. An important inference of this female-determining mechanism is that the tra loop is continuously active in the line of female descendants; tra gene products are expressed in the female germline and maternally inherited to switch zygotic tra ON. In zygotes committed to the male fate, this continuity is disrupted by paternally contributed male determiners, which interfere with maternal activation to leave zygotic tra, once transcribed, in the OFF state. Different male determiners evolved that are commonly referred to as $\mathrm{M}$ factors that are largely located on nonrecombining Y chromosomes. Alternatively, in Nasonia, loop activation by maternal tra relies on the presence of a paternal genome. It has been suggested that imprints in the maternal genome prevent activation of zygotic tra by maternal tra [Verhulst et al., 2010a, b]. Given that a female-determining mechanism based on maternal activation of tra is found in members of different insect orders (fig. 1), we consider it likely that it may have already existed before the divergence of the main insect orders and thus may reflect the ancestral state. In Drosophila and Apis, different types of feminizing signals evolved. Drosophila utilizes the presence of $2 \mathrm{X}$ chromosomes, and Apis deploys a heteroallelic combination of the complementary sex determination (csd) gene as the female-determining signal which imposes the productive splicing mode on tra (tra ON, fig. 1). Here, it is the absence of these feminizing signals, which causes tra to be spliced in the nonproductive mode (tra OFF), and as a result, male development follows. In Drosophila, the Sxl gene adopted the role of a key switch that is turned $\mathrm{ON}$ by a female signal ( 2 sets of X chromosomes) and selects and maintains the female fate throughout the individual's life cycle by a positive feedback loop. In this system, the active state of tra relies on continuous expression of the upstream activator $S x l$. When a male signal is present (1 set of X chromosome), $S x l$ remains OFF, and as a result, tra is spliced in the nonfunctional mode (fig. 1). However, the role of $S x l$ in Drosophila is not confined to the control of sex determination mediated by tra, but it is also involved in the control of an essential cellular mechanism that adjusts the difference in X-linked gene dose in XX and XY individuals [Cline, 1993]. It has been proposed that this vital function of $S x l$ preceded its recruitment to the sex-determining pathway [Bopp, 2010]. In the honeybee A. mellifera, 


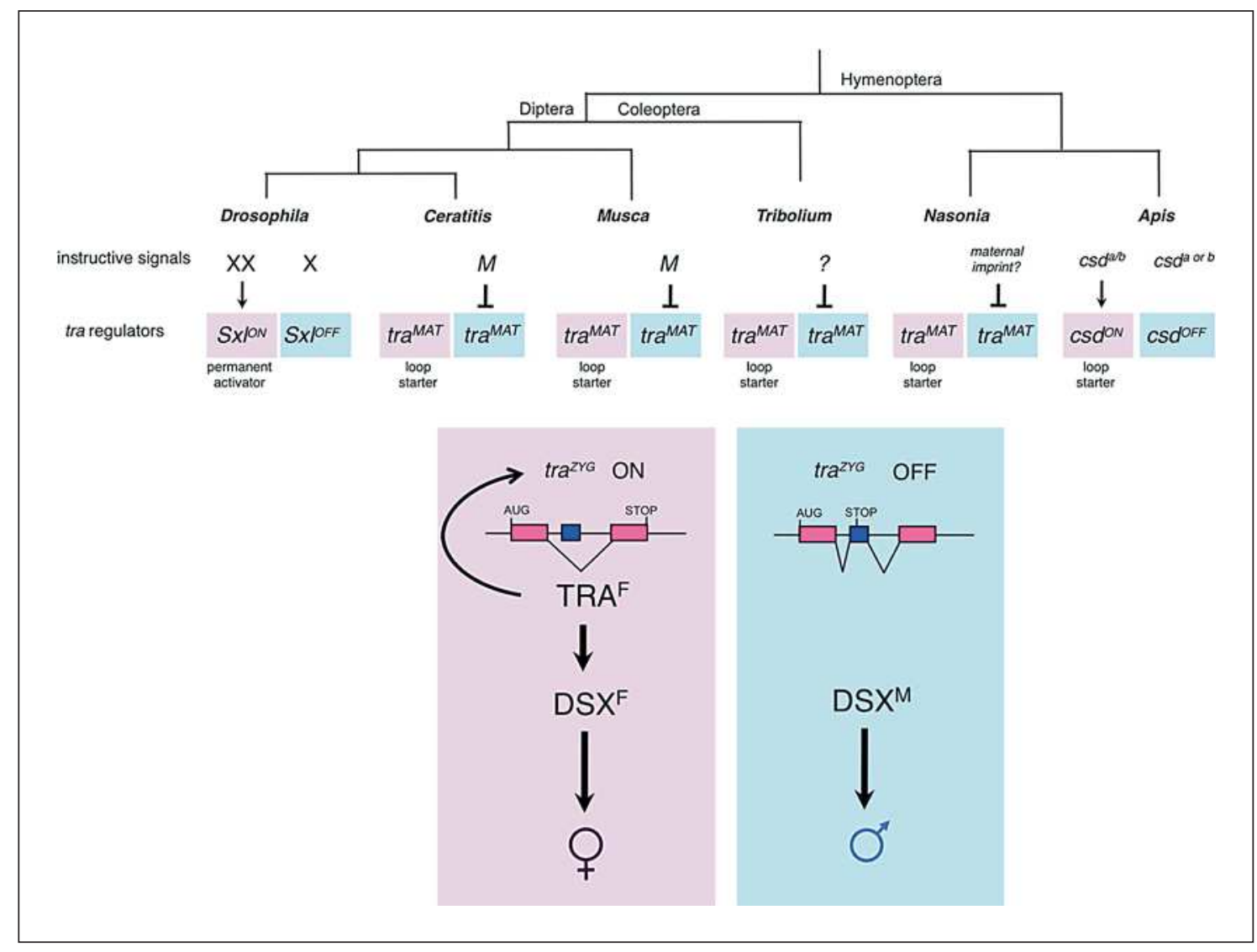

Fig. 1. A conserved principle in insect sex determination. This scheme illustrates the use of tra as a shared binary switch in sex determination in different holometabolous insects. In principle, activation of zygotic tra ( $\left.\operatorname{tra}^{Z Y G}\right)$ instructs female development by directing its downstream target, the global effector $d s x$, to express female-specific isoforms, DSX ${ }^{\mathrm{F}}$ (large pink box). When $\operatorname{tra}^{\mathrm{ZYG}}$ is kept in the OFF state, $d s x$ expresses male-specific isoforms $\left(\mathrm{DSX}^{\mathrm{M}}\right)$, which instruct male development (large blue box). ON/OFF regulation of $\operatorname{tra}^{Z Y G}$ is achieved by a regulatory splicing mechanism, which generates either splice variants with an intact open reading frame producing a functional protein $\left(\mathrm{TRA}^{\mathrm{F}}\right)$ or splice variants with added sequences/exons generating a nonfunctional open reading frame by introducing in-frame translational stop signals. Evolutionary diversification operates at the level of how this alternative splicing of $\operatorname{tra}^{Z Y G}$ is regulated. A prevalent feature found in

it is the heteroallelic combination of CSD variants that act as the female-determining signal. When present, it activates the feminizer gene ( $\mathrm{fem}$ ), the tra ortholog, and thereby engages a feedback loop to instruct female development [Beye et al., 2003; Gempe et al., 2009]. CSD proteins derived from hemizygous (haploid, unfertilized eggs) or homozygous csd alleles are nonactive, and as a result, fem is spliced in a nonproductive mode, which leads to male development. More than 15 allelic variants are segregat- several species is that, once activated, $\operatorname{tra}^{Z Y G}$ upholds the productive splicing mode by a positive feedback loop. Female-determining signals (small pink boxes) activate the $\operatorname{tra}^{Z Y G}$ feedback loop in the early zygote either by maternally provided $\operatorname{tra}\left(\operatorname{tra}^{M A T}\right)$ activity or by the presence of a heterozygous combination of $c s d$ alleles $\left(c s d^{a / b}\right)$. In the case of Drosophila female, female-specific splicing of tra is established and maintained by the continuous presence of active SXL. Male-determining signals such as M factors in Musca and Ceratitis or the absence of a paternal genome in Nasonia prevent activation of $\operatorname{tra}^{Z Y G}$ by $\operatorname{tra}^{M A T}$ (small blue boxes). In Apis and in Drosophila, where tra ${ }^{M A T}$ is not provided, absence of $\mathrm{tra}^{\mathrm{ZYG} \text { ac- }}$ tivators, such as SXL or the heteroallelic combination of csd alleles, conveys a male instruction resulting in $\mathrm{rra}^{Z Y G}$ splicing in the nonfunctional mode. 

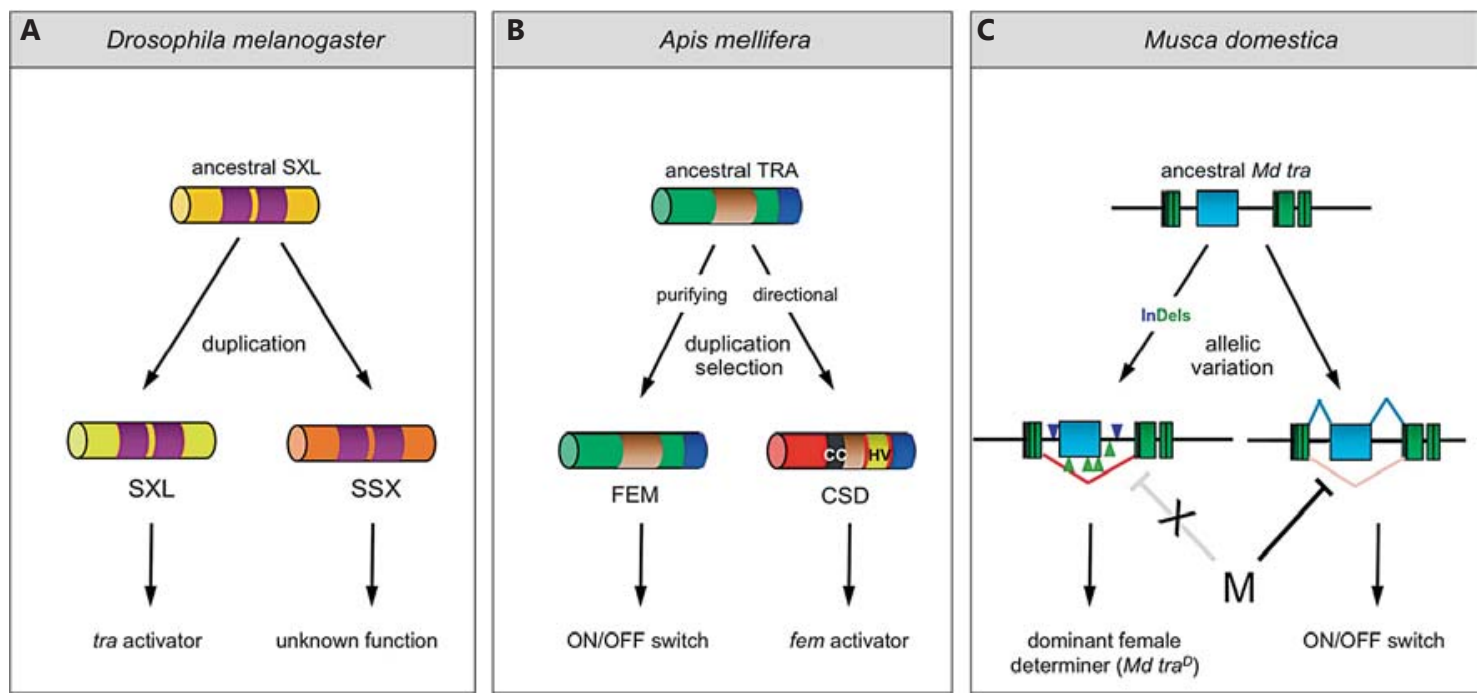

Fig. 2. Evolution of sex-determining signals. Different mutational routes can lead to the formation of novel sex-determining signals in insects. A $S x l$ gene originated by gene duplication in dipteran insects [Traut et al., 2006; Cline et al., 2010]. The encoded proteins of the 2 paralogs $S x l$ and $s s x$ are schematically presented (pink boxes denote the 2 RNA-binding domains). B The origin of the $c s d$ gene by tandem gene duplication from ancestral tra gene in the Apis lineage. Csd determines femaleness when heteroallelic CSD protein variants are present in the zygote. The encoding proteins are schematically presented. The emergence of the $c s d$ gene was accompanied by novel structural features such as the highly variable asparagine-/tyrosine-enriched repeat (denoted as $\mathrm{HV}=$ hypervariable region) and the putative coiled coil domain (denoted as CC) possibly involved in protein binding [Hasselmann and Beye, 2004; Hasselmann et al., 2008b]. Adaptive evolution (directional selection) was involved in shaping the new csd gene [Hasselmann et al., 2008a], while the paralogous sister gene fem evolved under purifying selection consistent with its ancestral female-promoting function [Hasselmann et al., 2010]. The brown box denotes the arginine-serine-enriched (RS) domain, and the blue box denotes the proline-rich domain. C The $M d t r a^{D}$ allele is a gain-offunction variant of the $M d$ tra gene in house flies [Hediger et al., 2010]. The Md tra gene structure is schematically presented. The wild-type allele is spliced in the female mode (red lines) unless a male determiner $(\mathrm{M})$ is present, which directs inclusion (blue lines) of a translation-terminating exon (blue). The lesions in the $M d \operatorname{tra}^{D}$ variant (blue triangles denote nucleotide insertions and green triangles nucleotide deletions) cause the pre-mRNA to be constitutively spliced in the female mode (red lines) irrespective whether an $\mathrm{M}$ is present or not. This novel feature converted Md tra into a dominant female determiner overriding the primacy of the ancestral male determiner. Modified from Gempe and Beye [2011] (Copyright Wiley-VCH Verlag GmbH \& Co KGaA. Preproduced with permission). effector in the silkmoth's sex determination pathway, there is clear evidence that regulation of $B m d s x$ involves splicing regulators not related to tra or tra2. Instead, $B m d s x$ appears to be controlled by a male-specific factor, BmIMP, a Bombyx homolog of IGF-II mRNA-binding protein (IMP) [Suzuki et al., 2010]. Because of the wide use of the tra-dsx module in holometabolous insects, we propose that, in the course of Bombyx evolution, the control of $d s x$ by tra may have been replaced by a novel BmIMP-based regulatory system. It will be of interest to examine whether, and if yes, to what extent this alternative system also operates in other lepidopteran species. Nevertheless, this finding shows that even the well-conserved transduction part is refractory to evolutionary changes adding to the plasticity in pathway architecture.

\section{Evolution of Sex Determination Mechanisms}

We will discuss here 3 examples of how sex-determining mechanisms evolved from the existing gene repertoire. Readers who are interested in the question why the sex determination pathway is evolving so fast are referred to a recent review [Gempe and Beye, 2011]. Functional and structural analysis of homologs of insect sex determination genes revealed that small-scale changes in cis-regulatory sequence in existing genes as well as in duplicated copies of genes can generate novel sex-determining signals (fig. 2). These new activities are deployed to regulate the key switch gene tra.

(1) Sxl gene in D. melanogaster encodes a RNA-binding protein that originated within the dipteran lineage by 
gene duplication of the ancestral sister-of Sex-lethal (ss $x$ ) gene (fig. 2A) [Traut et al., 2006; Cline et al., 2010]. Sxl took on the position of a new upstream component in the pathway, which directly controls splicing of tra [Sosnowski et al., 1989; Inoue et al., 1990; Samuels et al., 1994]. Cooption of $S x l$ to the pathway was possibly achieved by the emergence of new regulatory sites in the tra pre-mRNA that allowed SXL protein to effectively interact and impose the productive female splicing mode on tra [Bopp, 2010; Cline et al., 2010]. In this system, Sxl, once activated by the female signal (XX), maintains its own expression by an autoregulatory feedback loop throughout the female life cycle and hence substitutes for the need of tra autoregulation. The task of a master gene in the pathway that selects and maintains the female fate has been delegated to Sxl in Drosophila [Cline, 1984; Bell et al., 1991]. Though structurally well-conserved $S x l$ homologs have been identified in all insect systems studied thus far, a direct involvement of $S x l$ in tra regulation has only been confirmed in close relatives of $D$. melanogaster [Bopp et al., 1996; Cline et al., 2010]. This has led to the suggestion that $S x l$ 's recruitment to the sex-determining pathway is an evolutionary recent event that took place early in the course of divergence of the Drosophilidae family [Pane et al., 2002; Traut et al., 2006; Cline et al., 2010].

(2) The primary signal csd in honeybees evolved through tandem gene duplication of the ancestral copy of the $\mathrm{fem} / \mathrm{tra}$ gene some 20 million years ago (fig. 2B). The emergence of $c s d$ was accompanied by an insertion of a new hypervariable region that consists of asparagine-/tyrosine-enriched repeats that vary in numbers in the more than 15 different allelic specificities. The hypervariable region is thought to play a role in the recognition process of allelic differences. Six single nucleotide replacement changes in the ancestral progenitor gene formed a novel coiled coil motif in the csd gene [Hasselmann et al., 2008a, 2010]. The recent evolutionary origin of the csd gene in honeybees has allowed identifying signatures of selection [Hasselmann et al., 2008a, 2010]. The origin of $c s d$ was accompanied by an excess of nonsynonymous over synonymous, neutral nucleotide changes (fig. 2B) implying that positive selection played a role in forming a new sex determination mechanism. Intriguingly, some of these newly-fixed amino acid changes formed the putative coiled coil domain that appears to alter binding properties between allelic CSD proteins [Otte and Beye, unpubl. results]. The cause of directional selection during the evolutionary rise of $c s d$ is not understood. Possibly, the gradual degeneration of the preceding complementary sex de-

Sex Determination in Insects terminer may have selected for a new sex determiner [Hasselmann et al., 2008a; Gempe and Beye, 2011].

(3) In the housefly $M$. domestica, different sex-determining signals have been identified reflecting the plasticity of the sex determination pathway best [Dübendorfer et al., 2002]. There is the standard XX-XY system in which a dominant male determiner $\mathrm{M}$ on the $\mathrm{Y}$ chromosome prevents the maternal activation of zygotic tra. However, in natural populations, such $\mathrm{M}$ factors can be found on any of the 5 autosomes and even on the $\mathrm{X}$ chromosome [Tsukamoto et al., 1980; Franco et al., 1982; Denholm et al., 1983; Inoue et al., 1983; Inoue and Hiroyoshi, 1984]. It is debated whether these male determiners are transposed derivatives of the same gene or whether different genes have acquired the function of a dominant male determiner, of which the primary and sole role is to antagonize the establishment of the tra loop [Bopp, 2010]. In some populations, a dominant female determiner was identified which is a gain-of-function allele of the house fly tra gene. This allele harbors a number of multiple small deletions and insertions in intronic sequences which are believed to play a regulatory role in sex-specific splicing (fig. 2C) [Hediger et al., 2010]. This allele is constitutively spliced in the productive female mode even in the presence of the male determiner M. Hence, this new structural feature allowed tra to become uncoupled from the need of maternal activation. Instead, this allele became a dominant female determiner, which is epistatic to the male determiner $\mathrm{M}$.

\section{Downstream Events in Sexually Dimorphic Development}

Reproductive organ systems, secondary sexual characteristics and mating behaviors are amongst the most variable and changeable traits in animals, which evolve through sexual selection as described already by Darwin [1871] in his seminal essay on the 'descent of man'. Hence, another important consideration is how the conserved $t r a-d s x$ module is linked with the expression of sexually dimorphic traits and how it contributes to the bewildering variety of dimorphic features observed in insects. Studies on the divergence of sex-specific pigmentation and pheromone production in different Drosophila species show that small changes in the cis-regulatory elements of genes, which are directly regulated by $d s x$, are sufficient to generate new pigmentation and pheromone expression patterns [Carroll et al., 2008; Williams et al., 2008; Shirangi et al., 2009]. Much of the downstream di- 
vergence observed at the level of the differentiation genes, the immediate targets of the transcriptional effectors $d s x$ and $f r u$, can thus be explained by gains, modifications and losses of cis-regulatory sequences altering existing and/or defining new expression patterns which may eventually give rise to novel dimorphic traits. In addition, recent studies suggest that changes in temporal and spatial expression of $d s x$ by gene regulatory networks providing positional information may contribute to this diversity [Rideout et al., 2010; Robinett et al., 2010]. A prominent role of $d s x$ in properly implementing the selected sexual developmental program has not only been validated in $D$. melanogaster [Baker and Wolfner, 1988], but also in other dipterans, $M$. domestica [Hediger et al., 2004] and $C$. capitata [Saccone et al., 2008], in the lepidopteran B. mori [Suzuki et al., 2003, 2005] as well as in the coleopterans $T$. castaneum [Shukla and Palli, 2012a] and horned beetles [Kijimoto et al., 2012]. Hence, $d s x$ is thought to play a widely conserved role in integrating information about sexual identity in the general developmental program [Vincent et al., 2001].

\section{Concluding Remarks}

From these studies, we can infer a general principle of how sex-determining pathways evolved in insects. The pathways share a conserved core, which consists of a common binary switch, the tra gene, and at least one common executor downstream, the $d s x$ gene. This tra$d s x$ transduction module is likely to represent the ancestral part of the pathway. In the course of evolution, the instructive level diversified by coopting either feminizing or masculinizing signals to control the ON/OFF state of the tra gene. We here discussed how novel and different sex determination mechanisms evolved through smallscale nucleotide changes in regulatory and coding regions from existing or duplicated genes. For the $c s d$ signal in the honeybee, there is strong evidence that adaptive evolution has shaped the origin of this new system.

However, diversification occurred not only at the top level of the pathway, but also at the downstream level which is directly responsible for implementing the selected developmental program by shaping morphology, anatomy, physiology, and behavior of the 2 sexes. Diversification thus took place at both ends of the conserved signal-transducing cassette. We therefore suggest that the basic architecture of sex determination pathways in many insects is composed of a conserved transduction part in the middle with a variable instruction part at the top and

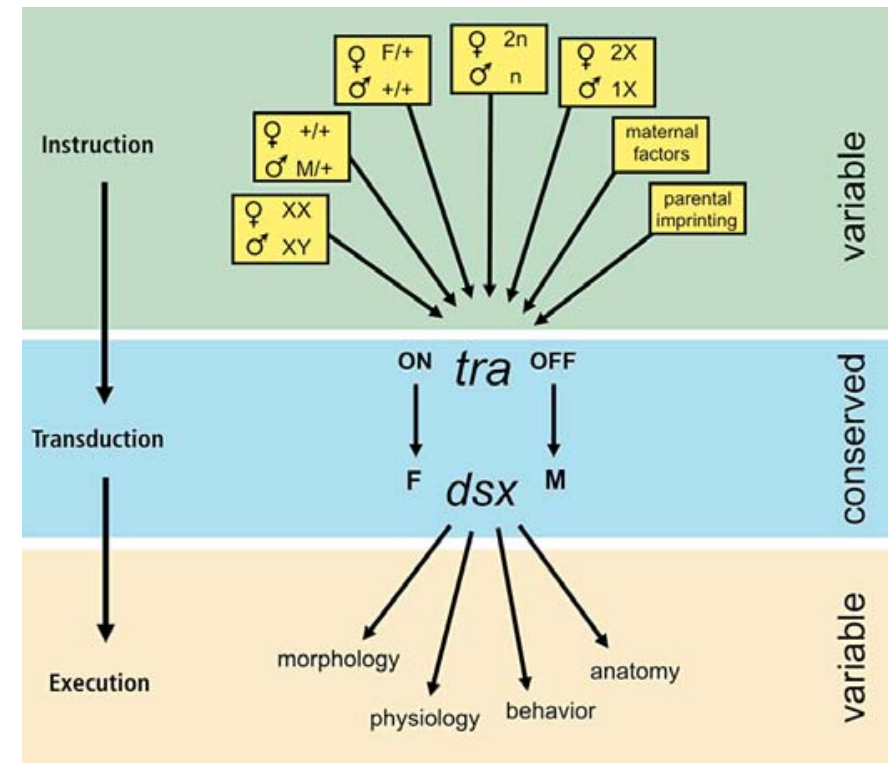

Fig. 3. An hourglass model for the divergence of sex-determining pathways in insects. The overall genetic architecture of sex determination pathways in holometabolous insects is best represented by an hourglass, which is composed of a conserved transduction part in the middle (blue), a variable instruction part at the top (green) and a variable execution part (yellow) at the bottom. Despite the existence of a bewildering variety of different instructive signals, the pathway transducing these signals in holometabolous insects share a conserved mechanism, which consists of a signalrelaying switch gene tra and at least one common executor, the $d s x$ gene. This tra-dsx transduction module (blue middle part) constitutes the ancestral core of the pathway. Evolutionary diversification took place at the 2 ends of this conserved module. In the course of evolution, the upstream primary signal, which controls tra, evolutionary diversified to produce a broad spectrum of different types of female and male signals of which only a selection is displayed in this scheme (green top part). Also, the regulatory events downstream of $d s x$, which are directly responsible for expressing dimorphic traits are likely to have diversified in the course of insect evolution. For instance, changes in the composition of targets downstream of $d s x$ are likely to have contributed to the extensively varied range of dimorphic phenotypes observed in insects [Carroll et al., 2008; Williams et al., 2008].

a variable execution part at the bottom (fig. 3). This model is best presented as an hourglass model with a constraint middle part that can be compared to other signaling pathways in which both ends are variable. Different ligands/receptors use the same cascade of intracellular mediators but trigger different patterns of transcriptional read outs depending on the cellular context.

Genetic and molecular excursions into pathways of different insect species give valuable insights into the evolutionary and regulatory mechanisms underlying the di- 
vergence of important developmental processes. A widespread and collaborative approach to understand sex determination in insects as presented in this review will greatly broaden our knowledge of how novel control mechanisms and regulatory principles evolved in developmental processes, an objective which cannot be achieved when studies are confined to a few traditional model systems.

Furthermore, the notion that sex determination pathways in insects converge and are built on conserved regulatory modules offers a useful concept for designing new genetic strategies in pest control management [Saccone et al., 2007; Morrison et al., 2010]. For instance, such splicing modules can be genetically modified and used to engineer strains carrying dominant female-specific lethal factors [Fu et al., 2007] or female-male-reverting factors which target disruption of the tra gene [Saccone et al., 2007]. The prospects are that the very same strategy can be applied to a wide range of pest insects, e.g. to produce male-only progeny in eradication programs that are based on the release of sterile insects [Dafa'alla et al., 2010].

\section{References}

Baker BS, Wolfner MF: A molecular analysis of doublesex, a bifunctional gene that controls both male and female sexual differentiation in Drosophila melanogaster. Genes Dev 2:477489 (1988).

Bell LR, Horabin JI, Schedl P, Cline TW: Positive autoregulation of Sex-lethal by alternative splicing maintains the female determined state in Drosophila. Cell 65:229-239 (1991).

Bertossa RC, van de Zande L, Beukeboom LW: The Fruitless gene in Nasonia displays complex sex-specific splicing and contains new zinc finger domains. Mol Biol Evol 26:15571569 (2009).

Beye M, Hasselmann M, Fondrk MK, Page RE, Omholt, SW: The gene $c s d$ is the primary signal for sexual development in the honeybee and encodes an SR-type protein. Cell 114: 419-429 (2003).

Bopp D: About females and males: continuity and discontinuity in flies. J Genet 89:315-323 (2010).

Bopp D, Calhoun G, Horabin JI, Samuels M, Schedl P: Sex-specific control of Sex-lethal is a conserved mechanism for sex determination in the genus Drosophila. Development 122:971-982 (1996).

Burtis KC, Baker BS: Drosophila doublesex gene controls somatic sexual differentiation by producing alternatively spliced mRNAs encoding related sex-specific polypeptides. Cell 56:997-1010 (1989).

Camerino G, Parma P, Radi O, Valentini S: Sex determination and sex reversal. Curr Opin Genet Dev 16:289-292 (2006).

Carroll SB, Prud'homme B, Gompel N: Regulating evolution. Sci Am 298:60-67 (2008).

Cline TW: Autoregulation functioning of a Drosophila gene product that establishes and maintains the sexually determined state. Genetics 107:231-277 (1984).

Cline TW: The Drosophila sex determination signal: how do flies count to two? Trends Genet 9:385-390 (1993).
Cline TW, Meyer BJ: Vive la différence: males vs females in flies vs worms. Annu Rev Genet 30: 637-702 (1996).

Cline TW, Dorsett M, Sun S, Harrison MM, Dines $J$, et al: Evolution of the Drosophila feminizing switch gene Sex-lethal. Genetics 186:13211336 (2010).

Clynen E, Ciudad L, Bellés X, Piulachs MD: Conservation of fruitless' role as master regulator of male courtship behaviour from cockroaches to flies. Dev Genes Evol 221:43-48 (2011).

Concha C, Scott MJ: Sexual development in $\mathrm{Lu}$ cilia cuprina (Diptera, Calliphoridae) is controlled by the transformer gene. Genetics 182 : 785-798 (2009).

Concha C, Li F, Scott MJ: Conservation and sexspecific splicing of the doublesex gene in the economically important pest species Lucilia cuprina. J Genet 89:279-285 (2010).

Dafa'alla, T, Fu G, Alphey L: Use of a regulatory mechanism of sex determination in pest insect control. J Genet 89:301-305 (2010).

Darwin C: The Descent of Man and Selection in Relation to Sex, ed 1 (D. Appleton and Company, New York 1871).

Denholm I, Franco MG, Rubini PG, Vecchi M: Identification of a male determinant on the $\mathrm{X}$ chromosome of housefly (Musca domestica L.) populations in South-East England. Genet Res 42:311-322 (1983).

Dübendorfer A, Hediger M, Burghardt G, Bopp D: Musca domestica, a window on the evolution of sex-determining mechanisms in insects. Int J Dev Biol 46:75-79 (2002).

Erickson JW, Quintero JJ: Indirect effects of ploidy suggest $\mathrm{X}$ chromosome dose, not the X:A ratio, signals sex in Drosophila. PLoS Biol 5:e332 (2007).

Franco MG, Rubini PG, Vecchi M: Sex-determinants and their distribution in various populations of Musca domestica L. of Western Europe. Genet Res 40:279-293 (1982).

Fu G, Condon KC, Epton MJ, Gong P, Jin L, et al: Female-specific insect lethality engineered using alternative splicing. Nat Biotechnol 25: 353-357 (2007).
Gempe T, Beye M: Function and evolution of sex determination mechanisms, genes and pathways in insects. Bioessays 33:52-60 (2011).

Gempe T, Hasselmann M, Schiøtt M, Hause G, Otte M, Beye M: Sex determination in honeybees: two separate mechanisms induce and maintain the female pathway. PLoS Biol 7:e1000222 (2009).

Hasselmann M, Beye M: Signatures of selection among sex-determining alleles of the honey bee. Proc Natl Acad Sci USA 101:4888-4893 (2004).

Hasselmann M, Gempe T, Schiøtt M, Nunes-Silva CG, Otte M, Beye M: Evidence for the evolutionary nascence of a novel sex determination pathway in honeybees. Nature 454:519-522 (2008a).

Hasselmann M, Vekemans X, Pflugfelder J, Koeniger N, Koeniger G, et al: Evidence for convergent nucleotide evolution and high allelic turnover rates at the complementary sex determiner gene of Western and Asian honeybees. Mol Biol Evol 25:696-708 (2008b).

Hasselmann M, Lechner S, Schulte C, Beye M: Origin of a function by tandem gene duplication limits the evolutionary capability of its sister copy. Proc Natl Acad Sci USA 107: 13378-13383 (2010).

Hediger M, Burghardt G, Siegenthaler C, Buser N, Hilfiker-Kleiner D, et al: Sex determination in Drosophila melanogaster and Musca domestica converges at the level of the terminal regulator doublesex. Dev Genes Evol 214:29-42 (2004).

Hediger M, Henggeler C, Meier N, Perez R, Saccone G, Bopp D: Molecular characterization of the key switch $F$ provides a basis for understanding the rapid divergence of the sex-determining pathway in the housefly. Genetics 184:155-170 (2010).

Inoue $\mathrm{H}$, Hiroyoshi $\mathrm{T}$ : Mapping of autosomal male-determining factors of the housefly, Musca domestica L., by using a female-determining factor. Jpn J Genet 59:453-464 (1984). 
Inoue $\mathrm{H}$, Fukumori $\mathrm{Y}$, Hiroyoshi T: Mapping of autosomal male-determining factors of the housefly, Musca domestica L., by means of sex-reversal. Jpn J Genet 58:451-461 (1983).

Inoue K, Hoshijima K, Sakamoto H, Shimura Y: Binding of the Drosophila Sex-lethal gene product to the alternative splice site of transformer primary transcript. Nature 344:461463 (1990).

Kijimoto T, Moczek AP, Andrews J: Diversification of doublesex function underlies morphsex-, and species-specific development of beetle horns. Proc Natl Acad Sci USA 109:2052620531 (2012).

Kuhn S, Sievert V, Traut W: The sex-determining gene doublesex in the fly Megaselia scalaris: conserved structure and sex-specific splicing. Genome 43:1011-1020 (2000).

Lagos D, Koukidou M, Savakis C, Komitopoulou $\mathrm{K}$ : The transformer gene in Bactrocera oleae: the genetic switch that determines its sex fate. Insect Mol Biol 16:221-230 (2007).

Meier N, Käppeli SC, Hediger Niessen M, Billeter JC, Goodwin SF, Bopp D: Genetic control of courtship behavior in the housefly: evidence for a conserved bifurcation of the sex-determining pathway. PLoS One 8:e62476 (2013).

Morrison NI, Franz G, Koukidou M, Miller TA, Saccone $\mathrm{G}$ et al: Genetic improvements to the sterile insect technique for agricultural pests. Asia-Pac J Mol Biol 18:275-295 (2010).

Nagaraju J, Saccone G: How is sex determined in insects? Preface. J Genet 89:269-270 (2010).

Ohbayashi F, Suzuki MG, Mita K, Okano K, Shimada T: A homologue of the Drosophila doublesex gene is transcribed into sex-specific mRNA isoforms in the silkworm, Bombyx mori. Comp Biochem Physiol B Biochem Mol Biol 128:145-158 (2001).

Oliveira DC, Werren JH, Verhulst EC, Giebel JD, Kamping A, et al: Identification and characterization of the doublesex gene of Nasonia. Insect Mol Biol 18:315-324 (2009).

O’Neil MT, Belote JM: Interspecific comparison of the transformer gene of Drosophila reveals an unusually high degree of evolutionary divergence. Genetics 131:113-128 (1992).

Pane A, Salvemini M, Delli Bovi P, Polito C, Saccone G: The transformer gene in Ceratitis capitata provides a genetic basis for selecting and remembering the sexual fate. Development 129:3715-3725 (2002).

Pane A, De Simone A, Saccone G, Polito C: Evolutionary conservation of Ceratitis capitata transformer gene function. Genetics 171:615624 (2005).

Rideout EJ, Dornan AJ, Neville MC, Eadie S, Goodwin SF: Control of sexual differentiation and behavior by the doublesex gene in Drosophila melanogaster. Nature Neurosci 13: 458-466 (2010).

Robinett CC, Vaughan AG, Knapp JM, Baker BS: Sex and the single cell. II. There is a time and place for sex. PLoS Biol 8:e1000365 (2010).

Ruiz MF, Eirín-López JM, Stefani RN, Perondini AL, Selivon D, Sánchez L: The gene doublesex of Anastrepha fruit flies (Diptera, Tephriti- dae) and its evolution in insects. Dev Genes Evol 217:725-731 (2007a).

Ruiz MF, Milano A, Salvemini M, Eirín-López $\mathrm{JM}$, Perondini AL, et al: The gene transformer of Anastrepha fruit flies (Diptera, tephritidae) and its evolution in insects. PLoS One 2:e1239 (2007b).

Saccone G, Pane A, Polito LC: Sex determination in flies, fruitflies and butterflies. Genetica 116 : 15-23 (2002).

Saccone G, Pane A, De Simone A, Salvemini M, Milano A, et al: New sexing strains for mediterranean fruit fly Ceratitis capitata: transforming females into males, in: Vreysen MJB, Robinson AS, Hendrichs J (eds): Area-Wide Control of Insect Pests: From Research to Field Implementation, pp 95-102 (Springer Verlag, Dordrecht 2007).

Saccone G, Salvemini M, Pane A, Polito LC: Masculinization of XX Drosophila transgenic flies expressing the Ceratitis capitata DoublesexM isoform. Int J Dev Biol 52:1051-1057 (2008).

Saccone G, Salvemini M, Polito LC: The transformer gene of Ceratitis capitata: a paradigm for a conserved epigenetic master regulator of sex determination in insects. Genetica 139: 99-111 (2011)

Salvemini M, Polito C, Saccone G: Fruitless alternative splicing and sex behaviour in insects: an ancient and unforgettable love story? J Genet 89:287-299 (2010).

Salvemini M, Mauro U, Lombardo F, Milano A, Zazzaro V, et al: Genomic organization and splicing evolution of the doublesex gene, a Drosophila regulator of sexual differentiation, in the dengue and yellow fever mosquito Aedes aegypti. BMC Evol Biol 11:41 (2011).

Samuels ME, Bopp D, Colvin RA, Roscigno RF, Garcia-Blanco MA, Schedl P: RNA binding by Sxl proteins in vitro and vivo. Mol Cell Biol 14:4975-4990 (1994).

Sánchez L: Sex-determining mechanisms in insects. Int J Dev Biol 52:837-856 (2008).

Sánchez L, Nöthiger R: Clonal analysis of Sex-lethal, a gene needed for female sexual development in Drosophila melanogaster. Roux Arch Dev Biol 191:211-214 (1982).

Sarno F, Ruiz MF, Eirin-López JM, Perondini AL, Selivon D, Sánchez L: The gene transformer-2 of Anastrepha fruit flies (Diptera, Tephritidae) and its evolution in insects. BMC Evol Biol 10:140 (2010).

Scali C, Catteruccia F, Li Q, Crisanti A: Identification of sex-specific transcripts of the Anopheles gambiae doublesex gene. J Exp Biol 208: 3701-3709 (2005).

Schütt C, Nöthiger R: Structure, function and evolution of sex-determining systems in Dipteran insects. Development 127:667-677 (2000).

Shearman DC, Frommer M: The Bactrocera tryo$n i$ homologue of the Drosophila melanogaster sex-determination gene doublesex. Insect Mol Biol 7:355-366 (1998).

Shirangi TR, Dufour HD, Williams TM, Carroll SB: Rapid evolution of sex pheromone-producing enzyme expression in Drosophila. PLoS Biology 7:e1000168 (2009).
Shukla JN, Nagaraju J: Doublesex: a conserved downstream gene controlled by diverse upstream regulators. J Genet 89:341-356 (2010).

Shukla JN, Palli SR: Doublesex target genes in the red flour beetle, Tribolium castaneum. Sci Rep 2:948 (2012a).

Shukla JN, Palli SR: Sex determination in beetles: production of all male progeny by parental RNAi knockdown of transformer. Sci Rep 2: $602(2012 b)$

Sosnowski BA, Belote JM, McKeown M: Sex-specific alternative splicing of RNA from the transformer gene results from sequence-dependent splice site blockage. Cell 58:449-459 (1989).

Suzuki MG, Ohbayashi F, Mita K, Shimada T: The mechanism of sex-specific splicing at the doublesex gene is different between Drosophila melanogaster and Bombyx mori. Insect Biochem Mol Biol 31:1201-1211 (2001).

Suzuki MG, Funaguma S, Kanda T, Tamura T, Shimada T: Analysis of the biological functions of a doublesex homologue in Bombyx mori. Dev Genes Evol 213:345-354 (2003).

Suzuki MG, Funaguma S, Kanda T, Tamura T, Shimada T: Role of the male BmDSX protein in the sexual differentiation of Bombyx mori. Evol Dev 7:58-68 (2005).

Suzuki MG, Imanishi S, Dohmae N, Asanuma M, Matsumoto S: Identification of a male-specific RNA binding protein that regulates sexspecific splicing of $B m d s x$ by increasing RNA binding activity of BmPSI. Mol Cell Biol 30: 5776-5786 (2010).

Traut W, Niimi T, Ikeo K, Sahara K: Phylogeny of the sex-determining gene Sex-lethal in insects. Genome 49:254-262 (2006).

Tsukamoto M, Shono T, Horio M: Autosomal sex-determining systems of the housefly: discovery of the first-chromosomal male factor in Kitakyushu, Japan. J UOEH 2:235-252 (1980).

Ullerich F-H: Analysis of sex determination in the monogenic blowfly Chrysomya rufifacies by pole cell transplantation. Mol Gen Genet 193: 479-487 (1984).

Verhulst EC, Beukeboom LW, van de Zande L: Maternal control of haplodiploid sex determination in the wasp Nasonia. Science 328:620623 (2010a).

Verhulst EC, van de Zande L, Beukeboom LW: Insect sex determination: it all evolves around transformer. Curr Opin Genet Dev 20:376383 (2010b).

Vincent S, Perkins LA, Perrimon N: Doublesex surprises. Cell 106:399-402 (2001).

Wilhelm D, Palmer S, Koopman P: Sex determination and gonadal development in mammals. Physiol Rev 87:1-28 (2007).

Wilkins AS: Moving up the hierarchy: a hypothesis on the evolution of a genetic sex determination pathway. Bioessays 17:71-77 (1995).

Williams TM, Selegue JE, Werner T, Gompel N, Kopp A, Carroll SB: The regulation and evolution of a genetic switch controlling sexually dimorphic traits in Drosophila. Cell 134:610623 (2008) 